\title{
Antioxidant activities and inhibitory effects of free and bound polyphenols from date (Phoenix dactylifera L.) seeds on starch digestive enzymes
}

\author{
Sameera Sirisena ${ }^{\mathrm{a}}, \mathrm{Ken}_{\mathrm{NG}}^{\mathrm{a}}$, And SAid AJlouni ${ }^{\mathrm{a}^{*}}$ \\ ${ }^{a}$ Biosciences Section, Faculty of Veterinary and Agricultural Sciences, University of Melbourne, Parkville, \\ Victoria 3010, Australia \\ ${ }^{*}$ Corresponding author \\ said@unimelb.edu.au \\ TEL: +613 8344-8620 \\ FAX: $+6138344-5037$
}

Received: 28 April 2016; Published online: 18 October 2016

\begin{abstract}
Date (Phoenix dactylifera L.) seeds have gained interest as a valuable by-product of the date fruit industry and have been identified as a rich source of functional and bioactive ingredients. In this study, date seeds from five varieties (Medjool, Deglet Nour, Barhee, Bou Sthammi and Dayrie) cultivated in Australia were analysed for their total phenolic and flavonoid contents, ferric reducing antioxidant power (FRAP), Trolox equivalent antioxidant capacity (TEAC), and in-vitro inhibition against $\alpha$-amylase and $\alpha$-glucosidase. The date seed powders (DSP) were extracted with acetone-methanol-water $(2: 2: 1, \mathrm{v}: \mathrm{v}: \mathrm{v})$ to obtain free polyphenols. The bound polyphenols were extracted from the residual solids with butanol$\mathrm{HCl}(97.5: 2.5 ; \mathrm{v} / \mathrm{v})$ treatment at $100{ }^{\circ} \mathrm{C}$. The greatest quantities of total phenols $(4166 \pm 227 \mathrm{mg}$ Gallic Acid Equivalents $100 \mathrm{~g}^{-1} \mathrm{DSP}$ ), total flavonoids (52.1 $\pm 9.6 \mathrm{mg}$ Quercetin Equivalents $\left.100 \mathrm{~g}^{-1} \mathrm{DSP}\right)$, FRAP $\left(1589 \pm 47 \mu \mathrm{mol}\right.$ Iron (II) Equivalents $\left.\mathrm{g}^{-1} \mathrm{DSP}\right)$ and TEAC (45.2 $\pm 1.4 \mu \mathrm{mol}$ Trolox Equivalents $\mathrm{g}^{-1}$ DSP) were detected in seeds from Deglet Nour variety.

Both free and bound polyphenol fractions showed significant $(\mathrm{p}<0.05)$ inhibition against rat intestinal $\alpha$-glucosidase with little or no inhibition against pancreatic $\alpha$-amylase. Bound polyphenols showed stronger $\alpha$-glucosidase inhibition compared with free polyphenols. The $\mathrm{IC}_{50}$ for $\alpha$-glucosidase were reported as mg GAE $\mathrm{mL}^{-1}$ ranged from $0.39 \pm 0.02$ (Deglet Nour) to $0.68 \pm 0.02$ (Medjool) for bound polyphenols, and from $0.907 \pm 0.08$ ( Medjool) to 1.75 \pm 0.15 (Barhee-khalal) for free polyphenols. Bound polyphenol fraction, with strong $\alpha$-glucosidase inhibition and weak $\alpha$-amylase inhibition, was suggested as a significant source of functional food ingredients with anti-hyperglycaemic properties.
\end{abstract}

Keywords: Date seed; Free polyphenols; Bound polyphenols; Type-2 diabetes

\section{Introduction}

The Date crop has been identified as a suitable crop for the arid regions of Australia, with a very good marketing potential for both date fruit industry and its by-products (Reilly, Reilly, \& Lewis, 2010) The total world production of date fruits was 7.5 million tons in 2012 (FAO-
STAT, 2015), and date seeds (approximately $10 \%$ of fruit weight) are an abundant by-product from this well-established industry (Besbes et al., 2004). Date fruit processing plants produce large quantities of date seeds as a result of value addition processing operations which involve pitting (deseeding) dates to manufacture dates filled with edible seeds, date paste and syrup. It has 


\section{Nomenclature}

$\begin{array}{ll}\text { BPP } & \text { Bound polyphenols } \\ \text { DSP } & \text { date seed powder } \\ \text { FPP } & \text { Free polyphenols }\end{array}$

FRAP Ferric reducing antioxidant power

\author{
PC Proanthocyanidins \\ TEAC Trolox equivalent antioxidant capacity \\ TFC Total flavonoid content \\ TPC Total phenol content
}

been suggested that utilizing this by-product in profitable ways will benefit the date industry (AlFarsi \& Lee, 2008a).

It has been reported that date seeds contain large amounts of polyphenols (Al-Farsi \& Lee, 2008b). Plant polyphenols are considered to be the key components responsible for many of the health benefits attributed to the consumption of fruits and seeds (Macedo et al., 2013; Mahbub et al., 2012; Gondoin, Grussu, Stewart, \& McDougall, 2010). Health benefits of consuming date seed products have been known in middleeastern folk medicine. Date seed infusions have been consumed in Turkey and Arab countries as herbal coffees with memory enhancing properties (Habib \& Ibrahim, 2009). A recent in-vitro study has indicated that date seed extracts can inhibit enzymes related to neurodegeneration (Sekeroglu et al., 2012). In-vivo studies on rats have shown that date seed extract could reduce DNA binding and methylation with N-Nitroso-N-methyl urea, which is a well known carcinogen (Diab \& AboulEla, 2012).

Anti-hyperglycaemic agents such as acarbose, which act by inhibiting starch digestion enzymes, such as $\alpha$-amylase and $\alpha$-glucosidase, are widely used in combination with drug treatment for Type 2 diabetes mellitus (Tundis, Loizzo, \& Menichini, 2010). Inhibition of $\alpha$-amylase and/or intestinal $\alpha$-glucosidase delays the rise in blood glucose levels, thus alleviating the complications arising from postprandial hyperglycaemia for diabetics. However, the generally prescribed antihyperglycaemic agents are strong $\alpha$-amylase inhibitors and are known to exert unpleasant side effects (flatulence, bloating, abdominal distention) due to suppression of starch digestion in the small intestine and bacterial fermentation in the colon (Yee \& Fong, 1996). Consequently, searching for more specific polyphenolic compounds from plant sources that could inhibit $\alpha$-amylase and $\alpha$-glucosidase might provide a solution to these side effects, and be cheaper and more tolerable alternatives. Plant polyphenols (free and bound) is expected to delay postprandial hyperglycaemia by specifically inhibiting intestinal $\alpha$-glucosidase (Phan, Wang, Tang, Lee, \& Ng, 2013), and provide additional benefits against oxidative diseases such as diabetics due to their antioxidant properties (Maritim, Sanders, \& Watkins, 2003).

Recent studies have demonstrated that the health benefits attributed to the plant polyphenols should include both free (also referred to as extractable) polyphenols (FPP) and bound (also referred to as non-extractable) polyphenols (BPP) (Saura-Calixto, 2012; Tow, Premier, Jing, \& Ajlouni, 2011). Most of the reported polyphenol contents considered the fraction extracted into aqueous-organic solvent system, whereas the residual solids are not analysed. However these residual solids have been found to contain a large amount of polyphenols including polymeric proanthocyanidins (PC). Some of the PCs are strongly bound to cell wall components (Hamauzu \& Mizuno, 2011), and Perez-Jimenez, Elena Diaz-Rubio, and Saura-Calixto (2013) indicated that BPPs contribute $60-90 \%$ to the total polyphenol content in most fruits. These studies have emphasised the importance of including the bound (non-extractable) polyphenols in plant polyphenol analysis.

The aim of this study was to determine the effect of date seeds' free and bound polyphenols 
on the activity of starch the digesting enzymes, $\alpha$-amylase and $\alpha$-glucosidase. The phenolic contents and antioxidant capacities of seeds from those Australian grown date varieties were also reported.

\section{Materials and Methods}

\section{$2.1 \quad$ Chemicals}

Acetone, butanol, ethanol, methanol, acetic acid, aluminium trichloride, dimethyl sulfoxide (DMSO), ferric chloride hexahydrate, hydrochloric acid, potassium acetate and potassium persulphate used were of the highest analytical reagent or chemical grade. Acarbose (A8980), 2,2'-azinoBis[3-ethylbenzo] thiazoline-6-sulfonic acid (ABTS), 3,5-Dinitrosalicylic acid (DNS), gallic acid, Folin-Ciocalteu reagent (F-C reagent, $2 \mathrm{~N})$, 6-hydroxy-2,5,7,8-tetramethylchromane-2carboxylic acid (Trolox; 238813), p-nitrophenyl$\alpha$-D-glucopyranoside (PNPG; N1377), 4nitrophenyl- $\alpha$-D-maltopentaoside $\quad$ (PNPG5; N1519), porcine pancreas $\alpha$-amylase (A3176), rat intestinal acetone powder (I1630), soluble potato starch (S9765 ), 2,4,6-tripyridyl-s-triazine (TPTZ T1253), and quercetin (Q4951) were purchased from Sigma-Aldrich Co, NSW, Australia.

\subsection{Preparation of date seed powder (DSP)}

Fruits of the Deglet Nour (also spelled Deglet Noor), Medjool, Bou Sthammi, Dayri in rutabmaturity stage, and Barhee varieties in both rutab and khalal stages, were kindly provided by Arid Zone Research Institute in Alice Springs. The botanical varieties were verified by molecular methods using established DNA markers (Dr Vivek Bhat, Senior Scientist, Arid Zone Research Institute, Alice Springs, Northern Territory 0870, Australia). Seeds were separated manually from the fruits (Figure 1) washed, then left to air dry for 5 days. Seeds were then ground using a cutting mill (Retsch SM100, Germany) to pass a $1 \mathrm{~mm}$ sieve.

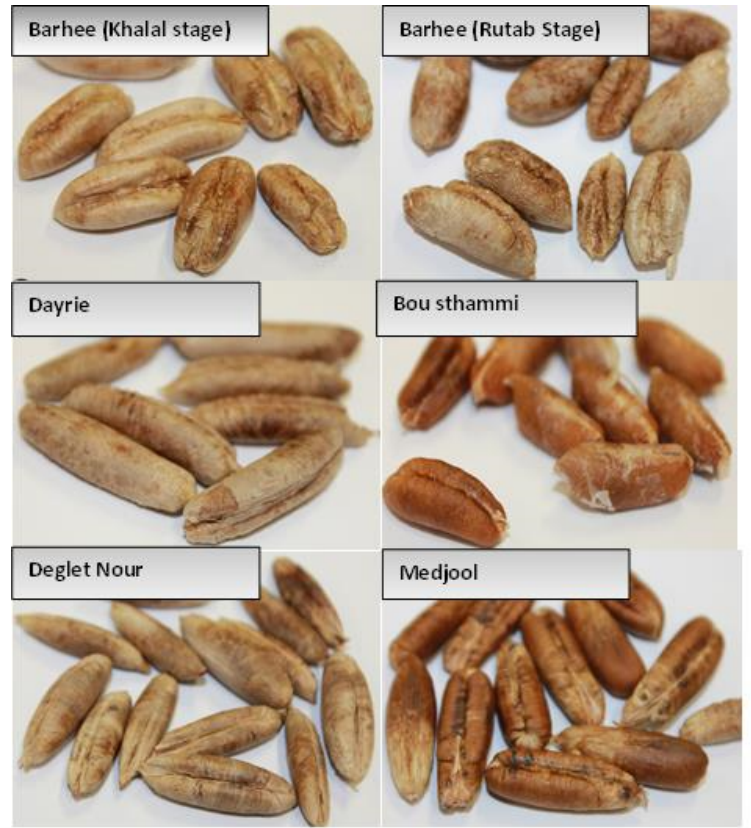

Figure 1: Date seeds from the studied varieties, including seeds from two maturity stages of Barhee (khalal-early and rutab-later stages)

\subsection{Preparation of free polyphenols (FPP) extract}

DSP (2 g) was mixed with $50 \mathrm{~mL}$ of acetone: methanol: water $(2: 2: 1, \mathrm{v}: \mathrm{v}: \mathrm{v})$, following method of (Al-Farsi \& Lee, 2008b) with modifications. The mixture was placed in a shaking incubator (Labwit ZWYR-240, China) at $40{ }^{\circ} \mathrm{C}$, at $150 \mathrm{rpm}$ for $1 \mathrm{~h}$ and centrifuged at 10,000 rpm for $10 \mathrm{~min}$. After 3 repeat extractions, the supernatants were combined and the solvent was rotary evaporated under vacuum at $40{ }^{\circ} \mathrm{C}$ (Buchi Vac V500 system, Switzerland). This concentrated FPP extract was re-dissolved in a minimum volume of water and freeze dried (Dyna Vac FD3, USA). The freeze-dried extract was stored at $-20{ }^{\circ} \mathrm{C}$ until further analysis. The solids remaining after the extraction were used for the extraction of BPPs. 


\subsection{Preparation of bound polyphenols (BPP) extract}

The generally used method for depolymerisation of the proanthcyanidins is HCl-butanol reaction with $\mathrm{Fe}^{3+}$ catalyst (Schofield, Mbugua, \& Pell, 2001). Following this reaction, the presence of $\mathrm{Fe}^{2+} / \mathrm{Fe}^{3+}$ ions in the final BPP extract was inevitable, thus rendering extract not suitable for subsequent analyses. Several trials showed that $\mathrm{Fe}^{2+} / \mathrm{Fe}^{3+}$ ions interfered with total flavonoid assay and antioxidant activity measurements using FRAP and TEAC assays. Therefore the depolymerisation was performed without the ferric chloride catalyst. Optimization of the extraction was monitored via measurements of TEAC and TPC, and photometric scans showed absorption maxima at $\lambda 550 \mathrm{~nm}$ characteristic to anthocyanidins which were significantly enhanced after $3 \mathrm{~h}$ of extraction (data not shown).

The residues from the FPP preparation were used for BPP extraction following the method of Perez-Jimenez and Saura-Calixto (2005), with modifications. From the FPP residue, $2 \mathrm{~g}$ was mixed with $25 \mathrm{ml}$ butanol/ $\mathrm{HCl}(97.5: 2.5 \mathrm{v} / \mathrm{v})$ and heated at $100{ }^{\circ} \mathrm{C}$ for 3 hours in a water bath. The mixture was centrifuged at 10,000 rpm for 10 minutes, supernatant was collected and residue was subjected to two washings with $10 \mathrm{~mL}$ butanol. Combined supernatants were rotary evaporated at $60{ }^{\circ} \mathrm{C}$, and $\mathrm{pH}$ of the concentrated extract was adjusted to $\backsim 4$ using $1 \mathrm{M}$ sodium hydroxide. $\mathrm{pH}$ above 5 caused precipitation of the extract, therefore $\mathrm{pH} 4$ was selected to maintain both an intact extract and the compatibility with buffers. Extract was freeze-dried and stored at $-20{ }^{\circ} \mathrm{C}$ until analysis.

\subsection{Total polyphenol content (TPC)}

Assay for total phenol content was based on reduction of the molybdenum-tungstate complex in F-C Reagent by phenols (Herald, Gadgil, \& Tilley, 2012). The procedure was adapted to 96 -well microplate platform $(250 \mu \mathrm{L}$ assay volume per well) with absorbance acquired at $\lambda 765$ $\mathrm{nm}$ using a microplate reader (Multiskan GO, Thermo Scientific, Australia) at $25{ }^{\circ} \mathrm{C}$. Gallic acid $(0-60 \mu \mathrm{g})$ was used to generate the standard plot, and TPC was expressed as mg Gallic Acid Equivalent (GAE) $100^{-1}$ g date seed powder (DSP).

\subsection{Total flavonoid content (TFC)}

Assay for total flavonoid content was based on chelation with $\mathrm{Al}^{3+}$ ion and absorbance measurement of the flavonoid- $\mathrm{Al}^{3+}$ complex as described by $\mathrm{Xu}$, Wang, $\mathrm{Hu}$, Lee, and Wang (2010), and was adopted to the microplate platform. Absorbance was acquired at $\lambda 430 \mathrm{~nm}$ instead of $415 \mathrm{~nm}$ based on our optimisation study, which showed that quercetin-aluminium complex exhibit maximum absorbance at $430 \mathrm{~nm}$ (data not shown). Quercetin $(0-30 \mu \mathrm{g})$ was used to generate the standard plot and TFC was expressed as mg Quercetin Equivalents (QE) $100^{-1} \mathrm{~g}$ DSP.

\subsection{Trolox equivalent antioxidant activity (TEAC)}

Free radical scavenging antioxidant activity was measured as TEAC using ABTS radical as the organic radical (Re et al., 1999). The assay was adapted to 96 well microplate platform and absorbance was measured at $\lambda 734 \mathrm{~nm}$ after $10 \mathrm{~min}$ at room temperature (RT). ABTS radical scavenging standard curve was obtained using Trolox $(0-400 \mu \mathrm{mol})$ and the TEAC expressed as $\mu$ mole Trolox Equivalents $\mathrm{g}^{-1}$ DSP.

\subsection{Ferric reducing antioxidant power (FRAP)}

Reducing antioxidant activity was measured as FRAP based on the reduction of $\mathrm{Fe}^{3+}$-TPTZ complex (Benzie \& Strain, 1996). The absorbance was measured at $\lambda 593 \mathrm{~nm}$ at a fixed incubation time of $10 \mathrm{~min}$ at RT. Reducing standard curve was obtained using $\mathrm{Fe}^{2+}$-TPTZ (0$500 \mu \mathrm{mol} \mathrm{Fe}{ }^{2+}$ ), and the FRAP was expressed as $\mu$ mol $\mathrm{Fe}^{2+}$ equivalents $\mathrm{g}^{-1}$ DSP. 


\section{$2.9 \quad \alpha$-Glucosidase assay}

$\alpha$-Glucosidase extract from rat intestine was prepared using rat intestinal acetone powder and activity assayed following the method of Kee, Koh, Oong, and $\mathrm{Ng}$ (2013). The protein content of the enzyme preparation was determined to be $12.65 \pm 0.81 \mathrm{mg} \mathrm{mL}^{-1}$ using the Lowry protein determination method. Date seed freeze dried extract was reconstituted in DMSO and 10-75 $\mu \mathrm{L}$ was mixed with $700 \mu \mathrm{L}$ of buffer $(0.1 \mathrm{M}$ potassium phosphate, $\mathrm{pH} 6.8+1 \%(\mathrm{w}: \mathrm{w}) \mathrm{NaCl}$ ) and $100 \mu \mathrm{L}$ of $\alpha$-Glucosidase (in the same buffer), and pre-incubated for 5 minutes at RT. A control (100\% enzyme activity) was prepared the same way with DMSO replacing the sample extract. Enzyme activity was compatible with $10 \%$ (v:v) DMSO with no inhibition of activity observed (data not shown). A colour correction solution was prepared for each extract with buffer replacing the enzyme to correct for background colour of extract. $100 \mu \mathrm{mol} \mathrm{L}{ }^{-1}$ of p-nitrophenyl $\beta$ D-glucopyranoside (PNPG) substrate was added to initiate the reaction, and the mixture was incubated at $37{ }^{\circ} \mathrm{C}$ for $1 \mathrm{~h}$. Reaction was terminated by chilling microplate on ice and the absorbance promptly measured at $\lambda 410 \mathrm{~nm}$ with spectrophotometer (Novaspec II, USA). The \% inhibition of $\alpha$-glucosidase activity was calculated using following equation:

$$
I=1-\frac{A b s_{c t r l}-A b s_{\text {extract }}}{A b s_{c t r l}} \times 100
$$

Where $\mathrm{I}$ is the $\%$ Inhibition, $A b s_{\text {ctrl }}$ is the Absorbance of control incubation corrected for enzyme color and $A b s_{\text {extract }}$ is the Absorbance of extract incubation corrected for extract and enzyme color

\section{$2.10 \alpha$-Amylase assay I (starch-DNS method)}

$\alpha$-Amylase activity was assayed by the starchDNS method according to Wan, Yuan, Cirello, and Seeram (2012) with some modifications. Porcine pancreas $\alpha$-amylase was diluted to 1 unit $\mathrm{mL}^{-1}$ in $20 \mathrm{mM}$ sodium phosphate buffer containing $7 \mathrm{mmol} \mathrm{L}^{-1} \mathrm{NaCl}$ and $1 \mathrm{mmol} \mathrm{L}^{-1}$ $\mathrm{CaCl}_{2}$. Soluble potato starch $(0.5 \%$; w:w) was prepared in the same buffer. $50 \mu \mathrm{L}$ Sample (in DMSO), $100 \mu \mathrm{L} \alpha$-amylase and $400 \mu \mathrm{L}$ buffer were mixed in $10 \mathrm{~mL}$ screw capped plastic tube and incubated for 5 minutes at RT. Enzyme activity was compatible with $10 \%$ (v:v) DMSO and no inhibition of activity was observed (data not shown). $500 \mu \mathrm{L} 0.5 \%$ starch solution (w:w) was added and mixture was incubated at $37^{\circ} \mathrm{C}$ for 20 min. then $500 \mu \mathrm{L}$ dinitrosalicylic acid (DNS) was added. Tube was placed in boiling water bath for 15 minutes. It was then cooled and absorbance was measured at $\lambda 540 \mathrm{~nm}$. A colour correction solution was prepared for each extract. Percentage inhibition of the $\alpha$-amylase activity was calculated using equation 1 .

\section{$2.11 \alpha$-Amylase assay II (PNPG5 method)}

$\alpha$-Amylase assay II was performed using the chromogenic substrate p-nitrophenyl- $\alpha$-Dmaltopentaoside (PNPG5) method as described by Funke and Melzig (2006) with modifications. Porcine pancreas $\alpha$-amylase was diluted to 50 units $\mathrm{mL}^{-1}$ in $20 \mathrm{mM}$ sodium phosphate buffer (pH 6.8), containing $7 \mathrm{mM} \mathrm{NaCl}$ and $1 \mathrm{mM}$ $\mathrm{CaCl}_{2}$. PNPG5 was made up to $25 \mathrm{mM}$ in the same buffer. The assay was performed in 96 well microplates. $50 \mu \mathrm{L}$ of PNPG5, $10 \mu \mathrm{L}$ of extract in DMSO, and $190 \mu \mathrm{L}$ buffer were added to each well, and $50 \mu \mathrm{L}$ of enzyme was added to initiate the reaction. Absorbance was measured at $\lambda 405$ $\mathrm{nm}$ using microplate reader at 3 minute intervals for 90 minutes. Absorbance of control (without inhibitor) and for extract background (without added enzyme) was also acquired. The percentage inhibition of amylase activity was calculated by the ratio of the linear gradients of control and extract incubation, using the linear range of the kinetic curve.

\section{$2.12 \quad \mathrm{IC}_{50}$ determination}

Active extracts against rat intestinal $\alpha$ glucosidase were assessed for their potency by their $\mathrm{IC}_{50}$ values. The data points (mean $\pm \mathrm{SD}$, $\mathrm{n}=3$ ) were fitted into a nonlinear sigmoid plot to take into account non-linear concentration dependent of enzyme inhibitor interaction at 
low and high concentrations (Burlingham \& Widlanski, 2003).

\subsection{Statistical analysis}

One-way analysis of variance (ANOVA) was used to analyse the data followed by Least Significant Difference $(\mathrm{LSD})$ test $(\mathrm{p}<0.05)$ for significant differences using SAS software (Version 9.2). Uncertainty of replicate determinations was reported as Standard Deviation in 2 significant figures according to EURACHEM guidelines (Ellison \& Williams, 2012).

\section{Results and Discussion}

As previously mentioned in the introduction (section 1), it is evident that analysis of antioxidant capacity and other health benefits derived from fruit polyphenolics must include both FPPs and BPPs. In this study we have taken into account FPPs and BPPs when discussing the polyphenol contents, antioxidant activity, and starchdigestive enzyme inhibition. BPP fraction has been subjected to acid-catalysed depolymerisation to study the above properties of the resulting degraded end-products.

\subsection{Total phenol and flavonoid content}

We found significant differences $(\mathrm{p}<0.05)$ between the total phenol contents (TPC) in FPP fractions of the date seed varieties (Table 1). Deglet Nour and Dayrie seeds showed significantly $(\mathrm{p}<0.05)$ high phenolic contents $(4166 \pm 227$ and $3777 \pm 309 \mathrm{mg} 100 \mathrm{~g}^{-1}$, respectively) compared with other varieties, whereas Medjool showed the lowest (2088 $\left.\pm 124 \mathrm{mg} 100 \mathrm{~g}^{-1}\right)$. Considerable levels of TPC were found in the BPP fractions in all varieties (Table 1 ). The TPC quantities in BPP fraction (reported as mg $100 \mathrm{~g}^{-1} \mathrm{DSP}$ ) were the greatest in Medjool seeds $(514 \pm 13)$, followed by Barhee (khalal) (405.9 \pm 9.2$)$, Barhee (rutab) $(378.9 \pm 8.9)$, Deglet Nour $(373 \pm 4.6)$ and Dayrie $(345.2 \pm 5.0)$.

The reported TPCs of date seeds in the literature varied due to different methodologies used in extraction and quantification, as well as varietal and geographic factors (Sirisena, Ng, \& Ajlouni, 2015). That was also evident in the current study where varieties differed significantly $(\mathrm{p}<0.05)$ in terms of phenolic contents. Most authors have reported very high TPC for the FPP of date seeds, ranging from 2000-4500 mg $100 \mathrm{~g}^{-1}$ DSP (Al-Farsi et al., 2007; Ardekani, Khanavi, Hajimahmoodi, Jahangiri, \& Hadjiakhoondi, 2010). The TPCs in the FPP of the Australian date varieties in this study sit within that range. The detected amounts of TPC in the FPP from Australian date seeds were greater than those reported in cocoa, chestnut, hazelnut, pecan nut and walnut seeds (1104, 2757, 687, 1816 and $1576 \mathrm{mg}$ GAE $100 \mathrm{~g}^{-1}$ dry weight), respectively (Perez-Jimenez, Neveu, Vos, \& Scalbert, 2010). Literature data were rather limited for comparing BPPs from seeds.

Since not all phenolic compounds are flavonoids, the flavonoids content are expected to be smaller than the phenolic contents. Results confirmed that analyses showed significantly $(\mathrm{p}<0.05)$ smaller quantities of TFCs in comparison with TPCs in both FPPs and BPPs (Table 1). The TFCs in Medjool seeds were the lowest $(9.4 \pm 0.58$ mg QE $100 g^{-1}$ DSP) in the FPPs, and the highest in the BPPs $\left(30.4 \pm 1.7 \mathrm{mg}\right.$ QE $\left.100 \mathrm{~g}^{-1} \mathrm{DSP}\right)$, while other varieties showed the opposite trend. Measuring flavonoids contents can provide an indirect assessment of its proportional contribution to the total phenols and also its contribution to antioxidant activity.

\subsection{Antioxidant properties of FPP and BPPs}

Antioxidant activity of food components can provide functionality contributing to disease prevention by reducing oxidative stress in the gastrointestinal tract and, if absorbed, in body tissues. The antioxidant capacity in the FPPs and BPPs of date seeds were evaluated using TEAC and FRAP assays. These analyses were based on the ability of antioxidants to scavenge (by electron or hydrogen atom donation) an organic free radical or to reduce iron, respectively.

Significant differences in antioxidant activity were observed between the seed varieties as measured by TEAC and FRAP (Table 1). For the 
218 | Sirisena et al.

FPPs, Deglet Nour and Dayrie seeds have the highest TEAC and FRAP, while Medjool seeds the lowest. FRAP values $\left(\mu \mathrm{mol} \mathrm{Fe}{ }^{2+}\right.$ Equivalents $\left.\mathrm{g}^{-1} \mathrm{DSP}\right)$ in Deglet Nour (1589 \pm 47$)$ and Dayrie $(1445.2 \pm 5.4)$ of seeds FPPs are in a similar range with those of Avacado and Longan seeds (1484 and $1388 \mu \mathrm{mol} \mathrm{Fe}{ }^{2+}$ Equivalents g, respectively) (Soong \& Barlow, 2004). Additionally, TEAC value of Deglet Nour seed FPP (45.2 \pm 1.4$)$ was rather similar to Avacado seed ( $42 \mu$ mole Trolox Equivalents $\mathrm{g}^{-1}$ ) and smaller than Longan seed (75 $\mu \mathrm{mol}$ Trolox Equivalents $\mathrm{g}^{-1}$ ) (Deng et al., 2012). However Al-Farsi et al. (2007) reported much larger TEAC values for Omani date varieties (580-929 $\mu \mathrm{mol}$ Trolox Equivalents $\mathrm{g}^{-1}$ fresh weight). With the exception of Medjool DSP, the TEAC values in BPPs were 2-4 folds smaller than in FPPs. Similarly, the FRAP values in BPPs of all DSP were 2-10 folds smaller than those in FPPs.

Strong positive correlations were observed for the TPC content of FPPs with the corresponding FRAP $\left(\mathrm{R}^{2}=0.97\right)$, and TEAC $\left(\mathrm{R}^{2}=0.95\right)$ values. TFC content also positively correlated with FRAP $\left(\mathrm{R}^{2}=0.98\right)$ and TEAC $\left(\mathrm{R}^{2}=0.97\right)$. Similar correlations were observed for BPPs (FRAP, $\mathrm{R}^{2}=0.89$; TEAC $\left.\mathrm{R}^{2}=0.98\right)$, indicating that the radical scavenging and ferric reducing properties of both FPPs and BPPs fractions are associated with phenolic and flavonoid compounds.

\subsection{Inhibition of carbohydrate hydrolysing enzymes}

Inhibition of intestinal $\alpha$-amylase and $\alpha$ glucosidase (membrane bound sucraseisomaltase and maltase-glucoamylase complexes) can prevent starch digestion and delay or reduce postprandial hyperglycaemia due to inhibition of starch digestion (Funke \& Melzig, 2006). Since control of hyperglycaemia is an essential treatment strategy for diabetes, $\alpha$-amylase and $\alpha$-glucosidase inhibitors play a role in the management of post-prandial hyperglycaemia (Tundis et al., 2010). Ideally, the drugs should have mild $\alpha$-amylase inhibition and moderate $\alpha$-glucosidase inhibition, which would minimize the side effects such as flatulence and abdominal pain caused by colonic fermentation of intact starch (Yee \& Fong, 1996).

\section{Inhibition of $\alpha$-glucosidase}

To our knowledge, no previous studies have reported the inhibitory effect of date seed extract against $\alpha$-glucosidase. However, El-Fouhil, Ahmed, and Darwish (2010) reported that diabetic rats fed on boiled aqueous date seed extract resulted in significant hypoglycaemia. In addition, Takaeidi et al. (2014) reported that methanolic date seed extract was able to promote the activities of serum paraoxonase (PON1) enzyme, which is known to be protective against oxidative stress related to diabetic complications. These studies pointed to the possible role of date seeds polyphenol in diabetic control.

We showed that BPPs from DSP inhibited rat intestinal $\alpha$-glucosidase (Table 2), ranging from 58 96\%, with BPPs from Deglet Nour seeds showing the strongest percentage inhibition $(96.1 \pm 1.9)$ at $1 \mathrm{mg}$ GAE $\mathrm{mL}^{-1}$. Inhibition from FPPs was moderate to low, ranging from 39-65\% at $1 \mathrm{mg}$ GAE $\mathrm{mL}^{-1}$, with FPPs from Medjool seeds showing the strongest percentage inhibition $(65.3 \pm 1.5)$. Acarbose, which was used as a positive inhibitor of $\alpha$-glucosidase, inhibited activity completely at a $1 \mathrm{mg} \mathrm{mL} \mathrm{mL}^{-1}$.

The $\mathrm{IC}_{50}$ values gave a clearer indication of the inhibitory potential of DSP against the $\alpha$-glucosidase (Table 3). The $\mathrm{IC}_{50}$ of FPPs from the seeds ranged from $0.907-1.75 \mathrm{mg}$ GAE $\mathrm{mL}^{-1}$, and again showing Medjool seeds with the strongest effect $\left(0.91 \pm 0.07 \mathrm{mg} \mathrm{GAE} \mathrm{mL}^{-1}\right)$. BPPs from DSP showed a much stronger inhibition (smaller $\mathrm{IC}_{50}$ ) than $\mathrm{FPP}$, with values ranging from 0.39-0.68 $\mathrm{mg}$ GAE $\mathrm{mL}^{-1}$. Deglet Nour $\mathrm{BPP}$ showed the strongest inhibition with $\mathrm{IC}_{50}$ value of $0.399 \pm 0.018 \mathrm{mg} \mathrm{GAE} \mathrm{mL}^{-1}$.

The difference in $\alpha$-glucosidase inhibitory effect between FPPs and BPPs from the seeds reflects on the different phenolic composition between the two phenolic fractions. Detailed characterisation of the FPP and BPP fractions of date seeds has been performed using UHPLC-MS in a separate study, which showed that FPPs constitute mainly simple and glycosylated phenolic acids, flavonols and flavanols, while the BPPs contained partially depolymerised proanthocyanidins and 
Table 1: Total phenol content (TPC), total flavonoid content (TFC), and antioxidant activities TEAC $^{3}$ and $\mathrm{FRAP}^{4}$ of free polyphenols (FPP) and bound polyphenols (BPP) from date seeds

\begin{tabular}{|c|c|c|c|c|c|c|}
\hline Polyphenols & Medjool & Deglet Nour & Barhee (Rutab) & Barhee (Khalal) & Bou Sthammi & Dayrie \\
\hline \multicolumn{7}{|l|}{ FPP } \\
\hline $\mathbf{T P C}^{1}$ & $2088 \pm 124^{a}$ & $4166 \pm 227^{b}$ & $2482 \pm 31^{c}$ & $3105 \pm 137^{d}$ & $2580 \pm 139^{c}$ & $3777 \pm 309^{b}$ \\
\hline $\mathbf{T F C}^{2}$ & $9.38 \pm 0.58^{a}$ & $52.7 \pm 9.6^{b}$ & $23.6 \pm 4.6^{c}$ & $32.1 \pm 2.0^{c}$ & $24.7 \pm 1.1^{c}$ & $47.9 \pm 6.0^{b}$ \\
\hline TEAC ${ }^{3}$ & $12.23 \pm 0.42^{a}$ & $45.2 \pm 1.4^{b}$ & $24.64 \pm 0.80^{c}$ & $25.28 \pm 0.23^{c}$ & $25.15 \pm 0.26^{c}$ & $41.38 \pm 0.65^{b}$ \\
\hline FRAP $^{4}$ & $635 \pm 34^{a}$ & $1589 \pm 47^{b}$ & $1157 \pm 40^{c}$ & $871 \pm 35^{d}$ & $894 \pm 17^{d}$ & $1445.2 \pm 5.4^{b}$ \\
\hline \multicolumn{7}{|l|}{ BPP } \\
\hline $\mathbf{T P C}^{1}$ & $514 \pm 13^{a}$ & $373.6 \pm 4.6^{d}$ & $378.9 \pm 8.9^{c}$ & $405.9 \pm 9.2^{b}$ & $369.0 \pm 8.2^{d}$ & $345.2 \pm 5.0^{d}$ \\
\hline $\mathbf{T F C}^{2}$ & $30.4 \pm 1.7^{a}$ & $13.8 \pm 2.5^{b}$ & $11.7 \pm 1.0^{b}$ & $14.6 \pm 2.1^{b}$ & $5.94 \pm 0.63^{c}$ & $5.97 \pm 0.40^{c}$ \\
\hline TEAC ${ }^{3}$ & $28.77 \pm 0.31^{a}$ & $12.86 \pm 0.40^{b}$ & $16.26 \pm 0.86^{c}$ & $13.1 \pm 1.1^{b}$ & $14.68 \pm 0.53^{d}$ & $12.7 \pm 1.1^{b}$ \\
\hline FRAP $^{4}$ & $197 \pm 12^{a}$ & $171.6 \pm 5.9^{a}$ & $155.7 \pm 4.2^{a}$ & $404.6 \pm 4.1^{b}$ & $238.1 \pm 2.0^{c}$ & $174 \pm 10^{a}$ \\
\hline
\end{tabular}

Values are reported as mean $\pm \mathrm{SD}(\mathrm{n} \geq 3)$ from replicates determination. Different letters ${ }^{a, b, c} \ldots$ within each row indicates significantly different means $(\mathrm{p}<0.05)$.

1- Total phenolic content was expressed as mg Gallic Acid Equivalents $100 \mathrm{~g}^{-1}$ dry date seed powder (DSP)

2- Total Flavonoid Content (TFC) was expressed as mg Quercetin Equivalents $100 \mathrm{~g}^{-1} \mathrm{DSP}$

3- Trolox equivalent antioxidant capacity (TEAC) values were expressed as $\mu$ mol Trolox Equivalents $\mathrm{g}^{-1} \mathrm{DSP}$

4 -Ferric reducing antioxidant power (FRAP) was expressed as $\mu \mathrm{mol} \mathrm{Fe}^{2+}$ equivalents $\mathrm{g}^{-1} \mathrm{DSP}$

simple phenolic acids including several dihydroxybenzoic acid isomers (unpublished data).

\section{Inhibition of $\alpha$-amylase}

We initially measured the inhibition of $\alpha$-amylase using the starch-DNS method according to literature ( $\alpha$-amylase assay I), but observed significant absorbance interference due reduction of the DNS reagent by polyphenols (data not shown). The reducing effect of polyphenols with DNS have been documented before (Xu, Leng, Wang, \& Zhang, 2012), thus this method is not suitable for the assay of $\alpha$-amylase activity with polyphenols. Therefore an alternative method was adapted using a chromogenic maltopentaoside substrate ( $\alpha$-amylase assay II), which is similar to the $\alpha$-glucosidase assay in that liberated $p$-nitrophenol is measured by absorbance to indicate enzyme activity.

Figure 2 shows the linear inhibitory kinetics of porcine pancreatic $\alpha$-amylase exhibited by FPPs and BPPs from Dayrie seeds as measured by $\alpha$ amylase assay II. Acarbose, used as a positive inhibitor of $\alpha$-amylase, almost completely inhibited activity at $1 \mathrm{mg} \mathrm{mL}^{-1}$. The percentage inhibition can be obtained by the ratio of the linear gradient of extract incubation over that of control incubation, which were $18.8 \%$ and $40.8 \%$ for

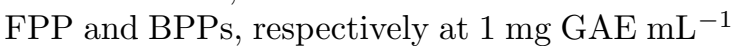
of Dayrie seed extract. Table 2 summarised the
$\% \alpha$-amylase inhibition by FPPs and BPPs for the other seed varieties. It showed that inhibition by BPPs (ranged from 9-57\%) were generally stronger than inhibition by FPPs (ranged from $7-18 \%$ ) for the same seed variety. Furthermore, the inhibition of $\alpha$-glucosidase was generally stronger than the inhibition of $\alpha$-amylase for the same seed variety. IC50 was not determined for $\alpha$-amylase due to the low inhibitory activity shown by both fractions.

The data did not show a clear correlation between $\alpha$-glucosidase and $\alpha$-amylase inhibition with phenolic content and antioxidant capacity of the FPP and BPP fractions. This could be due to different polyphenolic 'acids profile' of the 2 fractions. How polyphenols mediate enzyme inhibition still require more thorough investigation. At the molecular level, the number and position of free hydroxyl groups in the polyphenol structure play an important role in both $\alpha$ amylase and $\alpha$-glucosidase inhibition (Funke \& Melzig, 2006). Simple phenolic acids such as hydroxybenzoic acids and hydroxycinnamic acids were not inhibitory (Phan et al., 2013). Tannins showed mild inhibitory activity towards $\alpha$ amylase, but, ellagitannins with $\beta$-galloyl groups at the glucose $\mathrm{C}-1$ position showed a higher inhibition than those with $\alpha$-galloyl and desgalloyl compounds (Li, Tanaka, Zhang, Yang, \& Kouno, 2007). In a plant extract however, the 
Table 2: Inhibition of rat intestinal $\alpha$-glucosidase and porcine pancreatic $\alpha$-amylase by date seed free polyphenol (FPP) and bound polyphenol (BPP) extracts

\begin{tabular}{|c|c|c|c|c|}
\hline \multirow[t]{2}{*}{ Seed Variety } & \multicolumn{2}{|r|}{ EPP } & \multicolumn{2}{|r|}{ BPP } \\
\hline & $\alpha$-Glucosidase & $\alpha$-amylase & $\alpha$-Glucosidase & $\alpha$-amylase \\
\hline Deglet Nour & $47.4 \pm 1.4^{a}$ & $11.27 \pm 0.93^{a}$ & $96.1 \pm 1.9^{a}$ & $23.98 \pm 0.52^{a}$ \\
\hline Barhee (Khalal) & $39.65 \pm 0.66^{b}$ & $7.20 \pm 0.86^{b}$ & $68.26 \pm 0.49^{b}$ & $17.26 \pm 0.91^{c}$ \\
\hline Barhee (Rutab) & $43.24 \pm 0.73^{c}$ & $8.841 \pm 0.060^{c}$ & $58.79 \pm 0.62^{a}$ & $21.01 \pm 0.41^{c}$ \\
\hline
\end{tabular}

Percentage inhibition is relative to control without added inhibitor, and values listed are mean $\%$ inhibition \pm SD ( $\mathrm{n} \geq 3$ ) $a, b, c, d$ : Values sharing different superscript letters in a column are significantly different $(\mathrm{p}<0.05)$

Table 3: $\mathrm{IC}_{50}$ values for the inhibition of rat intestinal $\alpha$-glucosidase by FPP and BPP of date seed extract

\begin{tabular}{ccc}
\hline Date Seed Variety & $\begin{array}{c}\text { FPP } \\
\left.\text { (mg GAE } \mathbf{~ m L}^{-1} \text { reaction }\right)\end{array}$ & $\begin{array}{c}\text { BPP } \\
\left(\mathbf{m g ~ G A E} / \mathbf{m L}^{-1} \text { reaction }\right)\end{array}$ \\
\hline Deglet Nour & $1.28 \pm 0.16^{a}$ & $0.399 \pm 0.018^{a}$ \\
Dayrie & $1.483 \pm 0.089^{b}$ & $0.612 \pm 0.011^{b}$ \\
Barhee (Khalal) & $1.752 \pm 0.093^{c}$ & $0.585 \pm 0.091^{d}$ \\
Barhee (Rutab) & $1.23 \pm 0.75^{a}$ & $0.582 \pm 0.029^{d}$ \\
Bou Sthammi & $1.219 \pm 0.083^{a}$ & $0.648 \pm 0.038^{c}$ \\
Medjool & $0.907 \pm 0.072^{d}$ & $0.681 \pm 0.013^{c}$ \\
\hline
\end{tabular}

Values of $\mathrm{IC}_{50}$ reported are mean $\pm \mathrm{SD}(\mathrm{n}=3)$

$a, b, c, d$ : Values sharing different superscript letters in a column are significantly different $(\mathbf{p}<0.05)$

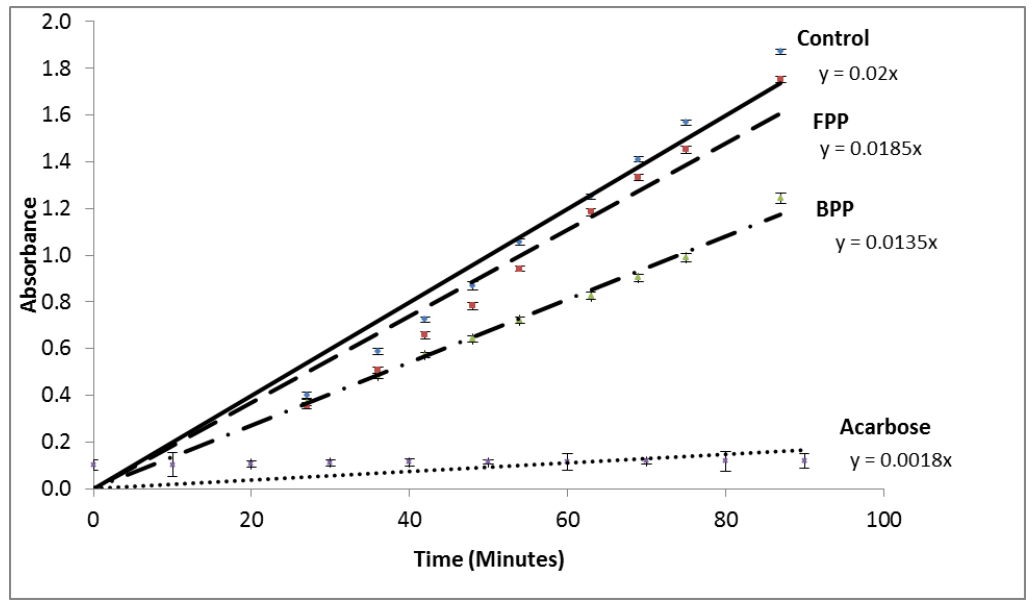

Figure 2: Inhibition of porcine pancreatic $\alpha$-amylase using PNPG5 as substrate ( $\alpha$-amylase assay II). The absorbance at different time points was plotted as mean \pm SD $(n \geq 3)$. FPP (long dash) and BPP (long dash and dot) of Dayrie variety at $1 \mathrm{mg} \mathrm{GAE} \mathrm{mL}^{-1}$ reaction was compared to control (solid line) without added inhibitor. Acarbose (dots) at $1 \mathrm{mg} \mathrm{mL}^{-1}$ reaction was used as a positive inhibition control 
mechanisms of inhibition might be enhanced by purported existence of synergistic action between polyphenols or other components which requires more thorough investigation. Stronger inhibitory activity of BPPs against $\alpha$-glucosidase may be attributed to the different phenolic profile obtained as a result of depolymerisation. Data on the chemical compositions of bound polyphenols in date seeds are very rare, which calls for further investigation of this area. Characterisation of phenolic profiles of FPPs and BPPs of the date seed is required to correlate inhibitory properties with specific compounds.

\section{Conclusions}

Our study showed that Australian date seeds have high polyphenol contents and in-vitro antioxidant activities. Bound polyphenol fraction from date seeds showed larger inhibitory capacity towards both starch digestive enzymes; $\alpha$-amylase and $\alpha$-glucosidase, compared to the free polyphenol fraction. Also, the bound polyphenol fraction showed strong inhibition towards $\alpha$-glucosidase but weak inhibition towards $\alpha$-amylase, indicating they are good source of functional ingredients with potent antihyperglycaemic properties.

\section{Acknowledgements}

Grinding date seeds was kindly assisted by AgriFood International, Werribee, Australia.

\section{References}

Ardekani, M. R. S., Khanavi, M., Hajimahmoodi, M., Jahangiri, M., \& Hadjiakhoondi, A. (2010). Comparison of antioxidant activity and total phenol contents of some date seed varieties from iran. Iranian Journal of Pharmaceutical Research, 9(2), 141-146.

Benzie, I. F. F. \& Strain, J. J. (1996). The ferric reducing ability of plasma (frap) as a measure of "antioxidant power": the frap assay. Analytical Biochemistry, 239(1), 7076. doi:10.1006/abio.1996.0292
Besbes, S., Blecker, C., Deroanne, C., Bahloul, N., Lognay, G., Drira, N. E., \& Attia, H. (2004). Date seed oil: phenolic, tocopherol and sterol profiles. Journal of Food Lipids, 11 (4), 251-265. doi:10.1111/j.1745-4522. 2004.01141.x

Burlingham, B. T. \& Widlanski, T. S. (2003). An intuitive look at the relationship of $\mathrm{k}-\mathrm{i}$ and ic50: a more general use for the dixon plot. Journal of Chemical Education, 80(2), 214-218.

Deng, G.-F., Shen, C., Xu, X.-R., Kuang, R.-D., Guo, Y.-J., Zeng, L.-S., ... Li, H.-B. (2012). Potential of fruit wastes as natural resources of bioactive compounds. International Journal of Molecular Sciences, 13(7), 8308-8323. doi:10 . 3390/ ijms13078308

Diab, K. A. S. \& Aboul-Ela, E. (2012). In vivo comparative studies on antigenotoxicity of date palm (Phoenix dactylifera l.) pits extract against dna damage induced by $n-$ nitroso-n-methylurea in mice. Toxicology International, 19(3), 279-286. doi:10.4103/ 0971 - 6580 . 103669. eprint: http: / / www . toxicologyinternational . com / article . asp? issn $=0971-6580 ;$ year $=2012 ;$ volume $=19$; issue $=3 ;$ spage $=279 ;$ epage $=286 ;$ aulast $=$ Diab; $=6$

Ellison, S. L. R. \& Williams, A. (2012). Eurachem/CITAC guide: Quantifying Uncertainty in Analytical Measurement. Retrieved from www.eurachem.org

FAOSTAT. (2015). Production quantities by country. Retrieved March 31, 2016. Retrieved from http: / / faostat3 . fao.org / download/Q/QC/E

Al-Farsi, M. A. \& Lee, C. Y. (2008a). Nutritional and functional properties of dates: a review. Critical Reviews in Food Science and Nutrition, 48(10), 877-887. doi:10.1080/ 10408390701724264

Al-Farsi, M. A. \& Lee, C. Y. (2008b). Optimization of phenolics and dietary fibre extraction from date seeds. Food Chemistry, 108(3), 977-985. doi:10.1016/j.foodchem. 2007.12.009

Al-Farsi, M., Alasalvar, C., Al-Abid, M., AlShoaily, K., Al-Amry, M., \& Al-Rawahy, F. (2007). Compositional and functional 
characteristics of dates, syrups, and their by-products. Food Chemistry, 104(3), 943947. doi:10.1016/j.foodchem.2006.12.051

El-Fouhil, A. F., Ahmed, A. M., \& Darwish, H. H. (2010). Hypoglycemic effect of an extract from date seeds on diabetic rats. Saudi medical journal, 31(7), 747-751.

Funke, I. \& Melzig, M. F. (2006). Traditionally used plants in diabetes therapy: phytotherapeutics as inhibitors of alpha-amylase activity. Revista Brasileira de Farmacognosia, 16(1), 1-5.

Gondoin, A., Grussu, D., Stewart, D., \& McDougall, G. J. (2010). White and green tea polyphenols inhibit pancreatic lipase in vitro. Food Research International, 43(5), 1537-1544. doi:10.1016/j.foodres.2010.04. 029

Habib, H. M. \& Ibrahim, W. H. (2009). Nutritional quality evaluation of eighteen date pit varieties. International Journal of Food Sciences and Nutrition, 60, 99-111. doi:10. 1080/09637480802314639

Hamauzu, Y. \& Mizuno, Y. (2011). Nonextractable procyanidins and lignin are important factors in the bile acid binding and radical scavenging properties of cell wall material in some fruits. Plant Foods for $\mathrm{Hu}$ man Nutrition, 66(1), 70-77. doi:10.1007/ s11130-010-0207-z

Herald, T. J., Gadgil, P., \& Tilley, A. (2012). High-throughput micro plate assays for screening flavonoid content and dpphscavenging activity in sorghum bran and flour. Journal of the Science of Food and Agriculture, 92(11), 2326-2331. doi:10 . $1002 /$ jsfa. 5633

Kee, K. T., Koh, M., Oong, L. X., \& Ng, K. (2013). Screening culinary herbs for antioxidant and alpha-glucosidase inhibitory activities. International Journal of Food Science and Technology, 48(9), 1884-1891. doi:10.1111/ijfs.12166

Li, H., Tanaka, T., Zhang, Y.-J., Yang, C.-R., \& Kouno, I. (2007). Rubusuaviins af, monomeric and oligomeric ellagitannins from chinese sweet tea and their alpha-amylase inhibitory activity. Chemical \& Pharmaceutical Bulletin, 55(9), 1325-1331. doi:10.1248/cpb.55.1325
Macedo, D., Tavares, L., McDougall, G. J., Stewart, D., Ferreira, R. B., Outeiro, T. F., ... Tenreiro, S. (2013). Polyphenols protect from alpha-synuclein toxicity by increasing autophagy and reducing reactive oxygen species in a yeast model of parkinson's disease. Yeast, 30(1), 204. 26th International Conference on Yeast Genetics and Molecular Biology, Frankfurt Main, Germany, Aug 29-Sep 03, 2013.

Mahbub, A., Le Maitre, C., Haywood-Small, S. L., McDougall, G., Cross, N. A., \& Jordan-Mahy, N. (2012). The anticancerous potential of polyphenols in the treatment of human myeloid and lymphoid leukaemia. Journal of Pathology, 228(1), S34. 202nd Summer Scientific Meeting of the Pathological-Society-of-Great-Britainand-Ireland, Univ Sheffield, Acad Unit Pathol, Sheffield, ENGLAND, JUL 03-05, 2012.

Maritim, A. C., Sanders, R. A., \& Watkins, J. B. (2003). Diabetes, oxidative stress, and antioxidants: a review. Journal of Biochemical and Molecular Toxicology, 17(1), 24-38. doi:10.1002/jbt.10058

Perez-Jimenez, J., Neveu, V., Vos, F., \& Scalbert, A. (2010). Identification of the 100 richest dietary sources of polyphenols: an application of the phenol-explorer database. European Journal of Clinical Nutrition, 64(3), S112-S120. 3rd International EruoFIR Congress 2009 - Eruopean Food Composition Data for Better Diet, Nutrition and Food Quality, Vienna, AUSTRIA, SEP 0810, 2009. doi:10.1038/ejcn.2010.221

Perez-Jimenez, J. \& Saura-Calixto, F. (2005). Literature data may underestimate the actual antioxidant capacity of cereals. Journal of Agricultural and Food Chemistry, 53(12), 5036-5040. doi:10.1021/jf050049u

Perez-Jimenez, J., Elena Diaz-Rubio, M., \& Saura-Calixto, F. (2013). Non-extractable polyphenols, a major dietary antioxidant: occurrence, metabolic fate and health effects. Nutrition Research Reviews, 26(2), 118-129. doi:10.1017/S0954422413000097

Phan, M. A. T., Wang, J., Tang, J., Lee, Y. Z., \& Ng, K. (2013). Evaluation of alphaglucosidase inhibition potential of some 
flavonoids from epimedium brevicornum. Lwt-food Science and Technology, 53(2), 492-498. doi:10.1016/j.lwt.2013.04.002

Re, R., Pellegrini, N., Proteggente, A., Pannala, A., Yang, M., \& Rice-Evans, C. (1999). Antioxidant activity applying an improved abts radical cation decolorization assay. Free Radical Biology and Medicine, 26(9-10), 1231-1237. doi:10 .1016 / S08915849(98)00315-3

Reilly, D., Reilly, A., \& Lewis, I. (2010). Towards an australian date industry: an overview of the australian domestic and international date industries. Rural Industries Research and Development Corporation.

Saura-Calixto, F. (2012). Concept and healthrelated properties of nonextractable polyphenols: the missing dietary polyphenols. Journal of Agricultural and Food Chemistry, 60(45), 11195-11200. doi:10 . 1021/jf303758j

Schofield, P., Mbugua, D. M., \& Pell, A. N. (2001). Analysis of condensed tannins: a review. Animal Feed Science and Technology, 91(1-2), 21-40. Conference on polyphenolics in tropical ruminant production, Bulawayo, Zimbabwe, Oct 11-14, 1999. doi:10. 1016/S0377-8401(01)00228-0

Sekeroglu, N., Senol, F. S., Orhan, I. E., Gulpinar, A. R., Kartal, M., \& Sener, B. (2012). In vitro prospective effects of various traditional herbal coffees consumed in anatolia linked to neurodegeneration. Food Research International, 45(1), 197203. doi:10.1016/j.foodres.2011.10.008

Sirisena, S., Ng, K., \& Ajlouni, S. (2015). The emerging australian date palm industry: date fruit nutritional and bioactive compounds and valuable processing byproducts. Comprehensive Reviews in Food Science and Food Safety, 14(6), 813-823. doi:10.1111/1541-4337.12162

Soong, Y. Y. \& Barlow, P. J. (2004). Antioxidant activity and phenolic content of selected fruit seeds. Food Chemistry, 88(3), 411-417. doi:10.1016/j.foodchem.2004.02. 003

Takaeidi, M. R., Jahangiri, A., Khodayar, M. J., Siahpoosh, A., Yaghooti, H., Rezaei, S., ... Mansourzadeh, Z. (2014). The effect of date seed (phoenix dactylifera) extract on paraoxonase and arylesterase activities in hypercholesterolemic rats. Jundishapur Journal of Natural Pharmaceutical Products, 9(1), 30-34.

Tow, W. W., Premier, R., Jing, H., \& Ajlouni, S. (2011). Antioxidant and antiproliferation effects of extractable and nonextractable polyphenols isolated from apple waste using different extraction methods. Journal of Food Science, 76 (7), T163-T172. doi:10. 1111/j.1750-3841.2011.02314.x

Tundis, R., Loizzo, M. R., \& Menichini, F. (2010). Natural products as alpha-amylase and alpha-glucosidase inhibitors and their hypoglycaemic potential in the treatment of diabetes: an update. Mini-reviews in Medicinal Chemistry, 10(4), 315-331.

Wan, C., Yuan, T., Cirello, A. L., \& Seeram, N. P. (2012). Antioxidant and alphaglucosidase inhibitory phenolics isolated from highbush blueberry flowers. Food Chemistry, 135(3), 1929-1937. doi:10 . 1016/j.foodchem.2012.06.056

Xu, H., Leng, X., Wang, M., \& Zhang, G. (2012). Glucose measurement in the presence of tea polyphenols. Food Analytical Methods, 5(5), 1027-1032. doi:10.1007/s12161-0119335- 9

Xu, M.-L., Wang, L., Hu, J.-H., Lee, S. K., \& Wang, M.-H. (2010). Antioxidant activities and related polyphenolic constituents of the methanol extract fractions from broussonetia papyrifera stem bark and wood. Food Science and Biotechnology, 19(3), 677-682. doi:10.1007/s10068-010-0095-x

Yee, H. S. \& Fong, N. T. (1996). A review of the safety and efficacy of acarbose in diabetes mellitus. Pharmacotherapy, 16(5), 792-805. 